East African Medical Journal Vol. 85 No. 3 March 2008

PATTERN AND CLINICAL CHARACTERISTICS OF FIREARM INJURIES.

W. A. Odhiambo, BDS, MDS, Lecturer, S. W. Guthua, BDS, MMed, DOMS, FIAOMS, FCS, Professor, M. L. Chindia, BDS, MSc., FFDRCSI, Associate Professor, Department of Oral and Maxillofacial Surgery, F. G. Macigo, BDS, MSc., Senior Lecturer, Department of Periodontology and Community Dentistry, College of Health Sciences, University of Nairobi, P. O. Box 19676 - 00202, Nairobi, Kenya

Request for Reprints to: Dr. W. A. Odhiambo, P.O.Box 21253 - 00505, Nairobi, Kenya

\title{
PATTERN AND CLINICAL CHARACTERISTICS OF FIREARM INJURIES
}

\author{
W. A. ODHIAMBO, S. W. GUTHUA, M.L. CHINDIA and F.G. MACIGO
}

\begin{abstract}
Objective: To determine the pattern and characteristics of patients admitted with firearm injuries (FAls) and establish the morbidity and mortality associated with these injuries.

Design: Retrospective cross-sectional study.

Setting: Kenyatta National Hospital (KNH), January 2004 to December 2005.

Subjects: All patients admitted with physically evident firearm injury.

Results: There were a total of 717 patients recorded with FAIs constituting $0.6 \%$ of the total number of patients seen in the casualty. Of these, $421(58.7 \%)$ were admitted and treated as in-patients. A firearm was used in $6.7 \%$ of the 6300 assault cases recorded in 2004 and in $9.7 \%$ of the 3079 cases recorded in 2005 . The increase from $6.7 \%$ in 2004 to 9.7\% in 2005 was statistically significant $(\mathrm{p}<0.05)$. There were $370(87.9 \%)$ males and 49 (11.6\%) females giving a male to female ratio of 7.5:1. The mean age was $29.7 \pm 10.9$ years with a range of 3 to 66 years. At least $262(62.2 \%)$ of the 421 admitted FAI casualties were treated under general anaesthesia (GA). The average duration of operation per patient was $2 \pm 1.5$ hours.

Conclusion: FAls are on the increase and affect all age groups but is largely a disease of a young male adult in the $3^{\text {rd }}$ and $4^{\text {th }}$ decade of life. Mortality is higher with increasing age while female victims are fewer but on average six years younger than males. The lower extremities are the commonest target among the survivors. However, abdominal wounds tend to be the most lethal, accounting for greater mortality.
\end{abstract}

\section{INTRODUCTION}

Firearm injury (FAI) is one of the leading causes of fatal and non-fatal injury in many countries. Research done in various countries has shown that firearm wounds tend to be more lethal and, therefore, cause higher mortality and severe morbidity rates than other weapons commonly used in assault (1-3). Of the non-fatal FAI that have been studied, spinal cord injuries and amputations are among the leading causes of permanent disability. Often, victims require expensive and time consuming surgery followed by weeks or months of hospitalisation and rehabilitation $(4,5)$. In Brazil, over $25 \%$ of spinal injuries are caused by firearms while in Finland, there is an average of 13 hospitalisation days for cases with mild to moderate FAI whereas in Los Angeles, FAI patients spend an average of ten days in hospital (6). A preliminary survey at the spinal injury hospital in Nairobi revealed that gunshot was the third most common cause of spinal injury after road traffic injuries (RTls) and falls from heights respectively. In Uganda, a study conducted at the Mbale regional hospital found that FAI patients had an average of 1.34 operations and stayed in hospital for an average of 14 days (7). Between 1994 and 1999, there were 225 gunshot injured cases admitted at the Kenyatta National Hospital $(\mathrm{KNH})$, accounting for $0.5 \%$ of the total hospital admissions during the period (8). These wounds caused by missiles lead to unique and complex injury patterns. Lower limb injuries predominate among the survivors. This is attributed to the high lethality of shots to the trunk and the craniofacial region (9-13). In the U.S.A firearms are the implement of choice for commission of both homicide and suicide with the craniofacial region as the favoured target $(14,15)$.

All over the world injury studies show an increasing preference for the gun as the weapon of choice for homicides and suicide. These studies have 
also shown that firearms are more lethal when compared to other portable and concealable weapons (16-18). The prevention and management of firearm wounds poses a challenge that can be appropriately tackled if there is improved understanding of the pattern of their occurrence and the risk factors involved. The main objective of this study was, therefore, to determine the pattern and characteristics of FAIs at the $\mathrm{KNH}$.

\section{MATERIALS AND METHODS}

This was a hospital-based cross-sectional study using patient records. Retrospective data were collected using a pre-designed data collection sheet. Patients admitted at KNH with FAIs between the period of January 2004 and December 2005 were included in this study. $\mathrm{KNH}$ is the largest national referral and university teaching hospital in Kenya and is located in the city of Nairobi. The hospital has a bed capacity for 1,200 patients with an annual patient turnover of over 80,000. Most cases of emergency trauma in Nairobi and the satellite districts are treated in this hospital. The computer coded treatment records of patients in the registry were used to trace the relevant files which were retrieved. Variables recorded included socio-demographic characteristicsincluding age, gender, occupation, and level of education of the victim, site, type and time of injury including complications and mortality, hours taken during the operation and total number of days of hospitalisation. Information regarding the perpetrator was also recorded. Data were then analysed using the statistical package for social sciences (SPSS) version 11.0 for windows program. Statistical tests of significance were computed where applicable. The study did not include pre-admission firearm injury mortality as these casualties are taken directly to the mortuary.

This study was approved by the $\mathrm{KNH}$ and University of Nairobi Ethics, Research and Standards Committee. Consent, reference number P154/9/2005 (KNH- ERC/01/3205) was granted.

\section{RESULTS}

General injury pattern: A total of 129,602 new patients were seen at the casualty during this period, among whom 22,146 (17.09\%) were injury cases (Table 1). FAIs were 717 making $0.6 \%$ of the total number of patients seen in the casualty and $3.2 \%$ of the injury cases. Of these 717 FAI cases, $421(58.7 \%)$ were admitted and treated as in-patients. A firearm was used in $6.7 \%$ of the 6300 assault cases recorded in 2004 and in $9.7 \%$ of the 3079 cases recorded in 2005. The increase from $6.7 \%$ in 2004 to $9.7 \%$ in 2005 was statistically significant $(\mathrm{p}<0.05)$.

Gender and age distribution of FAI casualties: Table 2 summarises the age and gender distribution of the $421 \mathrm{FAI}$ patients who were admitted. There were 370 $(87.9 \%)$ males and $49(11.6 \%)$ females giving a male to female ratio of 7.5:1. The mean age was $29.7 \pm 10.9$ years with a range of 3 to 66 years. The mean age for males was 30.3 years and that of females 24 years. This difference was statistically significant $(p<0.05)$. The peak injury age group for both males and females was 15 to 34 years.

The perpetrator of firearm violence was often identified by the victim as a thug or a robber $(66.4 \%)$, followed by police officers who were responsible for $22.6 \%$ of the injuries out of which $37(8.8 \%)$ were un-intentional by 'stray bullets'. While two people were shot by persons known to them and one was a case of self inflicted unintentional shooting. Occupation of the victim where indicated, most often a business person in $91(22 \%)$ cases or casual labourer in $64(15.2 \%)$ cases. The proportion of students injured $30(7.1 \%)$ was equal to that of security personnel or watchmen and those of informal employment were 32. There were 18 unemployed persons, four street boys and five suspected criminals included in the category of "others". Two hundred and thirty six patients had a recorded time of injury; $55.5 \%$ of them were injured between 19 and 24 hours. Majority were injured at 22, 21 and 20 hours in that order, (Table 3).

Distribution of FAIs by site: Three hundred and seventy eight $(89.9 \%)$ of the 421 had injury recorded in a single anatomical site (Table 4). Most patients had injury on the extremities (50.9\%), 20.1\% in the thorax and $17.3 \%$ in the abdomen. A total of 533 sites were injured, translating to 1.3 injured sites per patient.

Table 1

Annual distribution of injuries based on external cause

\begin{tabular}{|c|c|c|c|c|c|c|}
\hline \multirow[t]{2}{*}{ Cause of Injury } & \multicolumn{2}{|r|}{2004} & \multicolumn{2}{|r|}{2005} & \multicolumn{2}{|c|}{ Total } \\
\hline & No. & $(\%)$ & No. & $(\%)$ & No. & $(\%)$ \\
\hline Road Traffic Injuries & 8,520 & 57.2 & 4,134 & 57.1 & 12,654 & 57.1 \\
\hline Assault & 6,300 & 42.3 & 3,079 & 42.5 & 9,379 & 42.4 \\
\hline Rape & 84 & 0.6 & 29 & 0.4 & 113 & 0.5 \\
\hline Total & 14,904 & 100 & 7,242 & 100 & 22,146 & 100 \\
\hline
\end{tabular}


Table 2

Distribution of FAI patients by age and gender

\begin{tabular}{lccccc}
\hline Age (years) & Male & Female & $\mathrm{N} / \mathrm{I}^{*}$ & Total & $(\%)$ \\
\hline $0-14$ & 7 & 7 & & 14 & 3.2 \\
$15-24$ & 128 & 21 & & 149 & 35.3 \\
$25-34$ & 126 & 14 & & 141 & 33.4 \\
$35-44$ & 64 & 5 & 2 & 70 & 16.5 \\
$\geq 45$ & 39 & 1 & 42 & 10.0 \\
$\mathrm{~N} / \mathrm{I}$ & 6 & 1 & 2 & 7 & 1.6 \\
\hline Total & 370 & 49 & 21 & 100 \\
\hline
\end{tabular}

Table 3

Distribution of FAI victims according to the time of injury $(n=236)$

\begin{tabular}{lcc}
\hline Time (24hrs) & Frequency & $(\%)$ \\
\hline $1-06$ & 26 & 11.0 \\
$07-12$ & 25 & 10.6 \\
$13-18$ & 54 & 22.9 \\
$19-24$ & 131 & 55.5 \\
\hline Total & 236 & 100 \\
\hline
\end{tabular}

Table 4

Distribution of FAI based on the anatomical location of the injury $(n=532)$

\begin{tabular}{lccccc}
\hline Site & Singlesite & $(\%)$ & Multiple & Total & $(\%)$ \\
\hline Lower limbs & 148 & 39.5 & 31 & 179 & 33.6 \\
Thorax & 69 & 18.3 & 38 & 107 & 20.1 \\
Upper limbs & 63 & 16.7 & 29 & 92 & 17.3 \\
Abdomen & 40 & 10.6 & 34 & 74 & 13.9 \\
Maxillofacial & 23 & 6.1 & 10 & 33 & 6.2 \\
Neck & 5 & 1.3 & 9 & 14 & 2.6 \\
Cranium & 12 & 3.2 & 4 & 16 & 3.0 \\
Others & 2 & 0.5 & & 2 & 0.4 \\
N/I & 15 & 4.0 & & 15 & 2.8 \\
\hline Total & 378 & 100 & 155 & 533 & 100 \\
\hline
\end{tabular}

Duration of operation and number of days of hospitalisation: At least $262(62.2 \%)$ of the 421 admitted FAI casualties were treated under general anaesthesia (GA). The average duration of operation per patient was $2 \pm 1.5$ hours. Thirty percent of those treated under GA spent less than one hour intra-operatively, most of them for surgical debridement. The longest operation recorded took 13 hours. The average period spent in the hospital was 16.7 days with a range of 1 - 207 days (Figure 1).
Mortality due to FAIs: There were $38(9.0 \%)$ fatalities out of 421 patients admitted among whom 34(89.5\%) were male and four $(10.5 \%)$ female, giving a male to female ratio of 8.5:1 and translating to one death for every 11 FAI cases admitted. The mean mortality age was 34 years with an age range of 17 to 57 years. Twenty eight $(73.7 \%)$ patients of those who died had injury in a single site, most of them in the abdomen $(39.3 \%)$ followed by $21.4 \%$ in the spine (Table 5), while the remaining ten $(26.3 \%)$ had injury in two or more sites. Among the ten patients who died of multiple 
FAIs, five had injury in the chest and abdomen, while four had injury to the spine in combination with other sitesincluding one with multiplemaxillofacial injuries and another with head injury (HI).

\section{Figure 1}

\section{Distribution of FAI Patients' according to duration of hospitalisation}

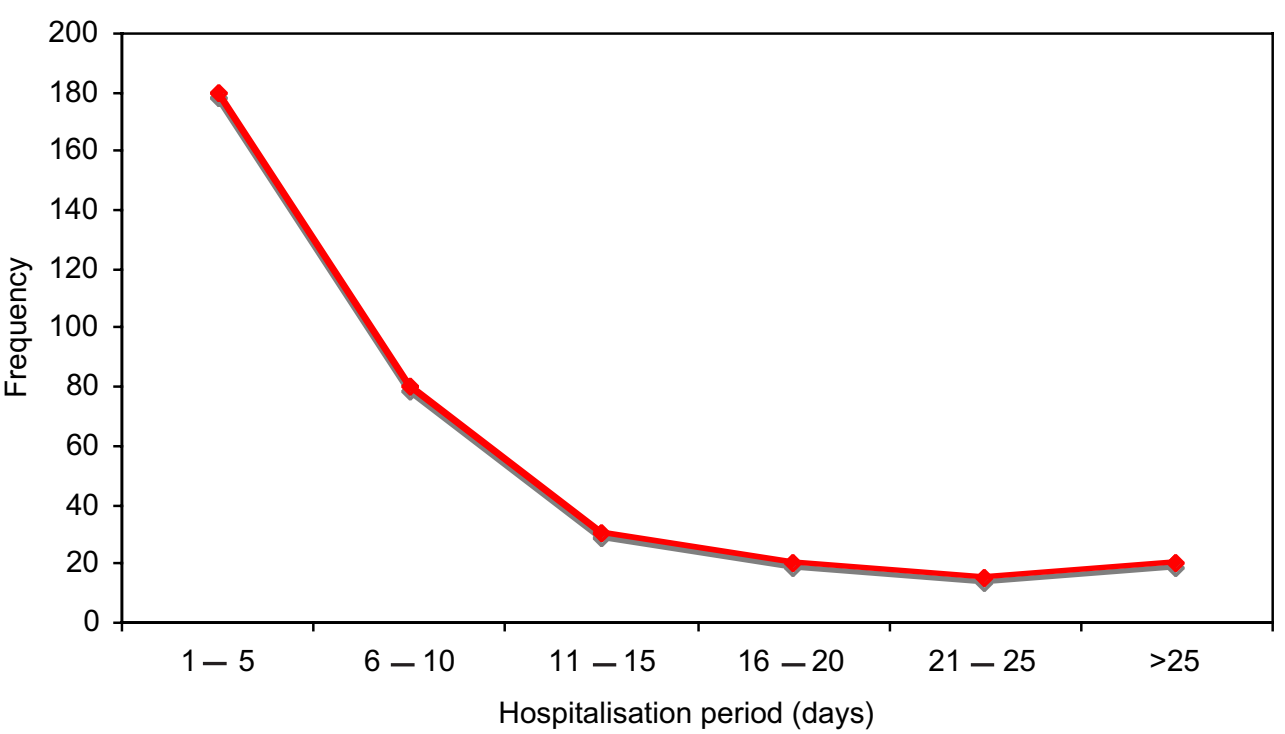

Table 5

FAI mortality according to the site of injury (Single site $n=28$ )

\begin{tabular}{lcccc}
\hline Site & 2004 & 2005 & Total & $(\%)$ \\
\hline Craniofacial & 3 & 2 & 5 & 17.9 \\
Spine & 3 & 3 & 6 & 21.4 \\
Abdomen & 6 & 5 & 11 & 39.3 \\
Chest & 1 & 1 & 2 & 7.1 \\
Lower Limbs & 1 & 3 & 4 & 14.3 \\
\hline Total & 14 & 14 & 28 & 100 \\
\hline
\end{tabular}

A total of $124(29.5 \%)$ of the 421 victims of FAI had a bullet or bullet fragment retained in their tissues, while in 284( $67.6 \%)$ there was no such evidence. In a small fraction of $2.9 \%$, the fate of the missile was not determined.

\section{DISCUSSION}

Firearm injury (FAI) remains largely a 'disease' of a young to middle age male. The age range most affected in this study was between 20 to 40 years, with a mean of 30 years for the patients who were admitted. These findings are comparable to several studies conducted in different parts of the world
$(10,14,17,18)$. In Kenya this trend seems to have remained the same for the past ten years (15). In the present study, female casualties were generally younger than the male with a mean age difference of 6.29 years.

In general there was a significant decrease in injuries managed at the KNH between 2004 and 2005 which is also true of assaults. Although there was also a decrease in cases of FAIs recorded, the proportion of assault cases in which a gunshot was used significantly increased from 6.7 to $9.7 \%$ $(p<0.05)$.This is consistent with the general global trend, showing an increasing use of a firearm as the weapon of choicein homicides (assaults) and suicides 
even in countries that reported a general decrease in assaults. A study in Kwazulu Natal in South Africa, over a five-year period (1987-1992) reported that whereas stab wounds had declined by $30 \%$, gunshot wounds had increased by more than $800 \%$ (1). Consistent with most reports from Africa, suicide by firearm is rare in Kenya and none was reported in this study, although there was one case of unintentional self inflicted FAI.

The number of days spent in hospital ranged from 1-207 days with an average admission period of 17 days. The average found in Uganda was 14 days, Finland 13 days and a study in USA reported a mean hospital stay of ten days $(18,21)$. It appears that the Kenyan FAI victim was likely to stay in hospital for three days to one week longer than those from the other countries. Those attacked at the work place were mostly businessmen and security attendants commonly known as watchmen followed by casual labourers. A previous study in $\mathrm{KNH}$ implicated robbery in $54.7 \%$ and police in $12.9 \%$, while that conducted at AKUH found that $74.7 \%$ of those admitted were victims of armed criminals $(8,9)$. Most of the injuries were reported to have occurred between $4 \mathrm{pm}$ and $11 \mathrm{pm}$ with the peak attacks recorded at 9 $\mathrm{pm}$ and $10 \mathrm{pm}$. This is important information for crime prevention and preparedness in the trauma care centres. Members of the public could be advised to avoid dangerous areas around these specific hours, while police patrol is increased.

Remarkably, there was one firearm death for every 11 cases of injury admitted. In El Salvador a higher mortality rate of one death for every five is reported (19) while the study in Finland found a mortality rate of $11 \%$ (18). These differences in mortality rates have been attributed to various factors, among them; site of injury and whether the injury was unintentional or intentional. In this study, shots to the abdomen and the spine were characterised by a higher mortality rate. Like in this study, the Finnish one also found extremities to have been the most commonly injured sites (47\%) among the FAI victims. However, they reported a higher incidence $(36 \%)$ of injuries to the craniofacial area. This high incidence of craniofacial injuries is possibly related to the use of firearms in suicide where the head and mouth are directly targeted (18). The mean age of the patients who died was 34 years with an age range of 17 to 57 years slightly higher than the entire sample mean of 30 years. However, this four - year difference in the mean age was not found to have been statistically significant.

Forty eight patients $(11.4 \%)$ in the current study had craniofacial injuries among whom there were seven $(14.6 \%)$ deaths. Nine of the patients had associated eye injury or injury to the orbit, four of whom suffered blindness in one or both eyes. Blindness can result from direct injury to the globe or optic nerve damage. The reported incidence of blindness in facial trauma is $2-5 \%$ (20). In this study the incidence of blindness was $1.2 \%$ of the total FAI, one of these was attributed to central loss of vision due to head injury (HI).

Thirty percent of the patients had a bullet or bullet fragment lodged in the tissues. Factors that determine the retention of a bullet in the tissues include, velocity of the missile, density of the target organ and the distance between the gun and the target. High energy transfer (HET) missiles shot at close range are likely to exit leaving behind large avulsive exit wounds while the low energy transfer (LET) missiles travelling through the bone or a thick muscle is likely to be retained (14). Whether bullets should be removed or left in the tissues depends on a number of factors: bullets may be left alone in the tissues if attempt to remove them exposes the patient to a high risk such as in asymptomatic intramyocardial bullets, intracranial or intra-spinal locations $(2,21,22)$. Bullet removal may be necessary in young children where continued growth may lead to drifting and even erosion of major blood vessels. They pose a problem during magnetic resonance imaging (MRI) and are associated with the risk of plumbism (23). It may also be necessary to remove bullets for the purposes of forensic ballistics. In some cases bullets may precipitate a foreign body reaction, abscess formation, osteomyelitis and pseudo- aneurysms. The fact that thirty percent of the FAI victims had a bullet lodged in their body, suggests that handguns with LET missiles might have been used in a significant number of these injuries.

In conclussion, firearm injuries are on the increase and affect all age groups but is largely a disease of the young male adults in the third and fourth decade of life. Mortality is higher with increasing age while female targets are fewer but on average six years younger than male. Lower extremities are the most common target among the survivors. However, abdominal wounds tend to be most lethal, accounting for greater mortality. The proportion of assault cases in which firearms were used increased between the years 2004 and 2005.

\section{ACKNOWLEDGEMENTS}

The authors are grateful to the Director, Kenyatta National Hospital for permission to conduct this study at the hospital.

This study was part of the thesis submitted for the award of the master of dental surgery degree in oral and maxillofacial surgery of the University of Nairobi and was approved by the KNH and University of Nairobi Ethics, Research and Standards Committee (reference no. pl 54/9/2005) 


\section{REFERENCES}

1. Muckart, D.J., Meumann, C. and Botha, J.B. The changing pattern of penetrating torso trauma in KwaZulu/Natal-a clinical and pathological review. S. Afr. Med. J. 1995; 85: 1172-1174.

2. Velmahos, G.C., Degiannis, E., Hart. K., Souter, I. and Saadia, R. Changing profiles in spinal cord injuries and risk factors influencing recovery after penetrating injuries. J. Trauma. 1995; 38: 334-333.

3. Coimbra, R., Prado, P.A., Araujo, L.H., et al. Factors related to mortality in inferior vena cava injuries: A 5 year experience. Int. Surg. 1994; 79: 138-141.

4. Annest, J.L., Mercy, J.A., Gibson, D.R. and Ryan, G.W. National estimates of non fatal firearm related injuries, Beyond the tip ofthe ice berg. J.A.M.A. 1995; 273: 1749-1754.

5. Odhiambo, W.A., Ayoti, O.J. and Guthua, S.W. The Burden of firearm injury in a developing country. Case presentation and review of the literature. 7th World Conference in Injury Prevention and Safety Promotion, Vienna 2004, pp.571.

6. WHO injuries and violence prevention department in Small Arms Global Health a contribution to UN conference on illicit trade in Small Arms and light Weapons, July 2001, pp.9-20.

7. Andrew, D.P., Olupot, P. and Neufeld, V.R: Health implications of small arms and light weapons in eastern Uganda. Presentation at the $8^{\text {th }}$ World Conference on Injury Prevention and Safety Promotion, Durban SA, April 2006.

8. Muhinga, M.N. A study of gunshot wounds as seen at Kenyatta National Hospital July 1994-June 1999 MMed (Surgery) Thesis 2000.

9. Saidi, H.S., Nyakiamo, J. and Faya, S. Gunshot Injures seen at Aga Khan Hospital Nairobi, Kenya. East Afr. Med. J. 2002; 79:188-192.

10. Ryan, J. Warfare Injuries Bailey and Love short practice of surgery 23rd Edition edited by Russel N.S.W and C.J.K Bulstrade Arnold Published 2000, pp 281-290.

11. Degiannis, E., Velmahos, G., Krawczykowski, D. et al. Penetrating injuries of the subclavian vessels. $\mathrm{Br}$. J. Surg. 1994; 81: 524-526.
12. Mock, C., Pilcher, S. and Maier, R. Comparison of the costs of acute treatment for gunshot and stab wounds: further evidence of the need for firearms control. J. Trauma. 1994; 36: 516-521.

13. Rizoli, S.B., Mantovani, M., Baccarin, V. and Vieira, R.W. Penetrating heart wounds. Int. Surg. 1993; 78: 229-230.

14. Banks. P., Terry, W., Whitlock, R.I.H., et al. Treatment of maxillofacial injuries in various theatres of war. Rowe and Williams Maxillofacial Injuries 1994; 2: 665-810.

15. Becellir, De. Ponte, F.S., Sessano, P.P. and Rinna, C. The firearm injuries to the maxillofacial region and reconstructive surgery J. Craniofac. Surg. 1995; 6: 473-476.

16. Muchae, A. Kenya crime survey 2002, security research and information centre, Alliance Express production 2002; 1: 22-32.

17. Rothlin, M., Vila, A. and Trentz, O. Results of surgery in gunshot and stab injuries of the trunk. Helvetica Chir. Acta. 1994; 60: 817-822.

18. Bostman, O., Marttinen, E., Makitie, I. and Tikka, S. Firearms injury in Finland 1985-1989: Ann. Chir. Gynae. 1993; 82: 47- 49 .

19. Ignacio, P., Emperatriz, C. and Ademar, A. Mauricio. Wounds Caused by Firearms in El Salvador,20042005: Epidemiological issues. Presentation at the 8th world Conference on Injury Prevention and Safety promotion, Durban SA, April 2006.

20. Girotto, J.A., Gamble, W.B., Robertson, B., et al. Blindness after reduction of facial fractures: Plastic Reconst. Surg. 1999;102:1821-1834.

21. Thompson, E.C., Block, E.F. and Mancini, M.C. Management of BB shot wounds to the heart. J. Trauma 1996; 40: 168-170.

22. Poston, R.S., Sloane, R.W. Jr., Morgan, B.R., et al. Elective removal of an intramyocardial bullet. South. Med. J. 2001; 94: 464-466.

23. Joseph, L.M., Stephen, J.R., Gracie, A.D., et al. Change in blood lead concentration up to 1 year after gunshot wound with a retained bullet. Am. J. Epidem. 2004; 159: 683-692. 